\title{
Factors associated with quality of life of postmenopausal women living in Iran
}

\author{
Soheila Nazarpour ${ }^{1}$, Masoumeh Simbar ${ }^{2 *}$, Fahimeh Ramezani Tehrani ${ }^{3}$ and Hamid Alavi Majd ${ }^{4}$
}

\begin{abstract}
Background: Quality of life (QoL) after menopause could be influenced by a host of personal and social factors. This study aimed to determine the factors associated with quality of life among postmenopausal women.

Methods: This cross-sectional study was conducted among 405 postmenopausal women selected using a multistage randomized sampling. The data-collection tools were the WHO Quality of Life-BREF (WHOQOL-BREF), the Menopause Rating Scale (MRS), and a researcher-designed questionnaire. The relationship between QoL and its potentially correlated factors was examined using t-test, ANOVA, Pearson's correlation, Spearman's correlation coefficient, and multiple linear regression.
\end{abstract}

Results: A negative correlation was found between the scores of QoL (total and all subscales) and the MRS total scores. The total scores of QoL were negatively correlated with duration of menopause $(r=-0.127, P=0.010)$, gravida $(r=-0.177, P<0.001)$, parity $(r=-0.165, P=0.001)$, frequency of stillbirth $(r=-0.104, P=0.037)$, vaginal delivery $(r=-$ $0.161, P=0.001)$, and waist-to-hip ratio $(r=-0.195, P<0.001)$. The QoL total scores were positively correlated with the educational level of the participants $(r=0.207, P<0.001)$ and that of their spouses $(r=0.160, P=0.001)$ along with their level of monthly family income $(r=0.218, P<0.001)$. Multiple-linear-regression analysis showed that the total score of QoL decreased with inadequate income, waist-to-hip ratio, and the total score of MRS.

Conclusions: Personal and social factors along with the severity of menopausal symptoms affect QoL postmenopause. These factors need to have a bearing on any effort to improve QoL among postmenopausal women.

Keywords: Menopause, Quality of life, Effective factors

\section{Background}

The World Health Organization defines quality of life (QoL) as "individuals' perception of their position in life in the context of the culture and value systems in which they live and in relation to their goals, expectations, standards and concerns $[1,2] . "$

Quality of life is a wide-ranging phenomenon that is affected in a complex way by an individual's physical health,

\footnotetext{
*Correspondence: msimbar@gmail.com

${ }^{2}$ Midwifery and Reproductive Health Research Center, Department of Midwifery and Reproductive Health, School of Nursing and Midwifery, Shahid Beheshti University of Medical Sciences, Vali-Asr Avenue, Cross of Vali-Asr and Hashemi Highway, Opposite to Rajaee Heart Hospital, Tehran 1996835119, Iran

Full list of author information is available at the end of the article
}

psychological state, level of independence, social relationships, and personal beliefs, along with their relationship to the salient features of their environment $[3,4]$.

QoL is also an aspect of health that plays a significant role in the conduct and evaluation of health interventions [5]. Thus research on QoL helps pave the way for more effective treatments and rehabilitative programs [6].

New developments in the medical sciences suggest that life expectancy has increased globally [7]. Today, many women spend a third of their lives after menopause [8]. Therefore, the QoL of postmenopausal women is of great public-health interest [9].

Menopause is an episode in women's lives that has physical, psychological, and social consequences, and thereby affects QoL. Symptoms experienced during

(c) The Author(s). 2020 Open Access This article is licensed under a Creative Commons Attribution 4.0 International License, which permits use, sharing, adaptation, distribution and reproduction in any medium or format, as long as you give appropriate credit to the original author(s) and the source, provide a link to the Creative Commons licence, and indicate if changes were made. The images or other third party material in this article are included in the article's Creative Commons licence, unless indicated otherwise in a credit line to the material. If material is not included in the article's Creative Commons licence and your intended use is not permitted by statutory regulation or exceeds the permitted use, you will need to obtain permission directly from the copyright holder. To view a copy of this licence, visit http://creativecommons.org/licenses/by/4.0/ The Creative Commons Public Domain Dedication waiver (http://creativecommons.org/publicdomain/zero/1.0/) applies to the data made available in this article, unless otherwise stated in a credit line to the data. 
menopause and socio-demographic characteristics affect OoL in postmenopausal women $[10,11]$.

The primary effects of menopause are associated with estrogen deficiency. The main health concerns of postmenopausal women include vasomotor symptoms, urogenital atrophy, osteoporosis, cardiovascular disease, cancer, decreased cognitive function, and sexual problems [12].

Hormonal changes that begin during the menopausal transition result in physiological changes and various other symptoms. For this reason, women often experience a wide range of symptoms, including hot flashes, insomnia, weight gain and bloating, mood swings, irregular menstruation, breast pain, depression, and headaches. These symptoms could be distressing, particularly as they occur at a time when women have important roles in society, within the family and at the workplace [13].

The menopause-related conditions lead to reduced quality of life among women [13, 14].

Several studies have revealed a set of factors that could be associated with QoL [11, 15]. Contradictions could nevertheless be found in different studies. The study aimed to find out the factors that are associated with quality of life of postmenopausal women.

\section{Methods}

\section{Study design}

This is a cross-sectional study of 405 postmenopausal women, aged 40 to 65 years, residing in the cities of Chalous and Noshahr, two cities located in northern Iran. This study began in October 2013 and ended in May 2014. This study is part of an extensive study of a $\mathrm{PhD}$ thesis.

The population of present study was the participants of a previous study conducted to evaluate the sexual function of postmenopausal women [16]. In these women, natural menopause had occurred over the past 3 years and they had no history of serious physical or mental illness. A stratified, multi-stage probability-cluster sampling was carried out through the probability-proportional-to-size (PPS) procedure.

Out of 620 postmenopausal women that were checked for inclusion criteria, 505 women (81.5\%), met our inclusion criteria, out of them 420 women agreed to participate in the study and signed the written informed consent; finally, 405 women returned the complete questionnaire.

The calculation of sample size was based on the population proportion $=0.60, \alpha=0.05, \varepsilon=0.1$ and the design effect of 1.5 .

The eligible women were explained about the study and invited to participate in the study. Those who agreed to participate completed the informed consent form.
The primary response rate of the postmenopausal women who were contacted, the eligibility rate among those who agreed to be participated, and the rate of participation among those found to be eligible were $82 \%, 96 \%$, and $98 \%$, respectively. The reason for not participating in the study may be due to menopausal complications.

\section{Measures}

A detailed researcher-designed questionnaire comprising questions about personal and social characteristics, the World Health Organization Quality of LifeBREF (WHOQOL-BREF) [17, 18], and the Menopause Rating Scale (MRS) [19-21] were completed by all of the participants over the course of face-to-face interviews. The questionnaires were anonymous and were filled out by interviewers who were trained by the researchers and had sufficient information about the subject, enabling them to explain ambiguous cases to the participants.

The WHOQOL-BREF questionnaire, which measures overall QoL and particular aspects of it, has four domains of physical health, psychological health, social relations, and environment. The questionnaire contains 24 questions to assess these aspects of QoL, and two more questions about an individual's overall perception of their QoL and health. After performing the calculations, a score ranging from 4 to 20 is obtained for each domain, and a score ranging from 16 to 80 is obtained as a total score, with higher scores indicating better QoL. These scores are in turn convertible to score points in the range of 0 to $100[17,18]$.

This tool has been developed in more than 15 countries and translated into multiple languages, with the questions' concepts remaining the same in all of its versions [22]. In Iran, the standardization of the questionnaire was conducted by Nejat et al. [23], the results of which demonstrated the reliability and validity of the tool among healthy and patient groups. In Soltani et al.'s study also Cronbach's alpha was calculated as 0.84 for this questionnaire [24] In present study its reliability was assessed using the test-retest method, resulting in a Cronbach's alpha and intraclass correlation coefficient (ICC) of 0.921 and 0.968 , respectively.

The Menopause Rating Scale (MRS) is a standard scale for rating the severity of menopausal symptoms in the three categories of somatic (vasomotor), psychological, and urogenital symptoms. The questionnaire consists of 11 questions, the responses to which are scored on a 5score scale for the symptoms' severity, including "none" (0), "mild" (1), "moderate" (2), "severe" (3) and "very severe" (4). A total score $\geq 17$ is taken as indicating severe menopausal symptoms [19]. The validity and reliability of the Persian version of the questionnaire was confirmed by 
Masjoudi et al. In this study Internal consistency was 0.83 based on Cronbach's alpha indicating the high reliability of the scale [25]. For the purposes of our study, the validity of the MRS was confirmed using content and face validity, and its reliability was assessed using the test-retest method, yielding a Cronbach's alpha and intraclass correlation coefficient (ICC) of 0.933 and 0.977 , respectively.

The researcher-designed questionnaire consisted of 28 questions about anthropometric, socio-demographic and reproductive characteristics. The heights and weights of the women were measured using the calibrated Balance Beam Doctor/Physician Scale with Height Rod (Detecto 439, 400 lbs., Made in the USA) (Amazon 2017), and then were used to calculate body mass index (BMI) $(\mathrm{kg} / \mathrm{m} 2)$.

\section{Statistical analysis}

The relationship between QoL and its potentially correlated factors was assessed using $t$-test, ANOVA, Pearson's correlation (for the normal-distribution quantitative variables), Spearman's correlation coefficient (for the categorical variables), and multiple linear regression. The data were analyzed using the statistics software SPSS (version 18). The level of significance was set at $P$ less than 0.05 .

For the multiple-linear-regression models, we assumed that the personal and social factors along with the severity of menopausal symptoms were related to scores of QoL (total score and the scores of its domains). In these analyses, total QoL score and the scores of its domains (in separate calculations) were taken as the dependent variable. The independent variables in our model, which were entered as indicators, included the total score of MRS, age, duration of menopause, gravida, parity, frequency of vaginal delivery, frequency of stillbirth, waistto-hip ratio, BMI, occupation, husband's job, educational level of the women and that of their spouses, and level of monthly family income. These variables have been shown by other studies to be related to QoL [11, 26-37]. All of these variables except for age and frequency of vaginal delivery remained in the model. In our regression analyses, R2 equaled 0.271 , which showed that $27.1 \%$ of our outcome variable (total score of QoL) was explained by the variables included in the regression model. The interactions between the independent variables were also assessed, even though they were not included in the final model as they were not statistically significant.

\section{Results}

Five hundred and five postmenopausal women participated in the study. The average age of the participants was $52.8 \pm 3.7$ (mean $\pm \mathrm{SD}$ ) years. The demographic and anthropometric characteristics of the participants were as follows: $51.2 \pm 3.5$ years for age at menopause, $19.8 \pm$ 14.4 months for duration of menopause, $29.5 \pm 5.5$ for
BMI $(\mathrm{Kg} / \mathrm{m} 2), 0.9 \pm 0.1$ for waist-to-hip ratio, $4.7 \pm 2.3$ for number of pregnancies, and $4.1 \pm 2.0$ for number of deliveries. $80.0 \%$ of the participants were housewives and the educational level of most of them was low (63.5\% were illiterate or merely knew reading and writing). Monthly household income was less than adequate in $65.4 \%$ of the women (Table 1 ).

The total score of QoL was $54.53 \pm 7.18$ (in the range of 30.0 to 71.0). The highest and lowest scores belonged to the physical-health domain $(14.28 \pm 2.41$ in the range of 7.0 to 19.0) and the psychological-health domain $(12.75 \pm 2.07$ in the range of 7.0 to 18.0$)$, respectively.

Our analysis of the MRS questionnaires yielded a mean \pm SD total MRS score of $12.45 \pm 7.20$. The psychological and urogenital domains accounted for the highest and lowest scores, respectively $(4.90 \pm 3.45$ and $3.10 \pm 2.46$, respectively). Overall, $29.1 \%$ of the participants reported severe menopausal symptoms $(\geq 17)$.

The total scores of QoL were found to be in a significant negative correlation with the total scores of MRS and the scores in all of its domains (somatic, psychological and urogenital $)(P<0.001)$. All QoL domain scores were also negatively correlated with the total

Table 1 Distribution of anthropometric, socio-economic and reproductive characteristics $(N=405)$

\begin{tabular}{|c|c|}
\hline Variables & Mean \pm SD/N (\%) \\
\hline Age (years) & $52.8 \pm 3.7$ \\
\hline Age at menopause ${ }^{a}$ (years) & $51.2 \pm 3.5$ \\
\hline Duration of menopause (months) & $19.8 \pm 14.4$ \\
\hline Duration of marriage (years) & $32.6 \pm 6.4$ \\
\hline $\mathrm{BMI}(\mathrm{Kg} / \mathrm{m} 2)$ & $29.5 \pm 5.5$ \\
\hline Waist to Hip Ratio & $0.9 \pm 0.1$ \\
\hline Gravida $^{b}$ & $4.7 \pm 2.3$ \\
\hline Parity $^{c}$ & $4.1 \pm 2.0$ \\
\hline \multicolumn{2}{|l|}{ Occupation } \\
\hline Housewife & $324(80.0)$ \\
\hline Employed & $81(20.0)$ \\
\hline \multicolumn{2}{|l|}{ Husband's job } \\
\hline Employed & $303(75.0)$ \\
\hline Retired or unemployed & $101(25.0)$ \\
\hline \multicolumn{2}{|l|}{ Education } \\
\hline Illiterate or merely reading and writing & $257(63.5)$ \\
\hline Diploma and under diploma & $112(27.7)$ \\
\hline Higher diploma & $36(8.9)$ \\
\hline \multicolumn{2}{|l|}{ The adequacy of Monthly household income } \\
\hline Less than adequate & $265(65.4)$ \\
\hline Adequately or More & $136(33.6)$ \\
\hline
\end{tabular}

${ }^{a}$ Menopause is defined as the time when there has been no menstrual periods for 12 consecutive months; ${ }^{b}$ Number of pregnancies; ${ }^{c}$ Number of deliveries 
scores of MRS. Saving the environment domain of QoL - which did not show a significant correlation with the somatic domain of MRS - there was a significant negative correlation between the scores in the QOL domains (physical health, psychological health, social relations) and the scores in the MRS domains (Table 2).

The duration of menopause was found to be reversely correlated with the total score of QoL $(P=0.010, r=-$ $0.127)$ and the scores of the psychological-health and environment domains $(P<0.05)$. The age of the women and their spouses, menopausal age, and duration of marriage were not found to be significantly correlated with the QoL scores (Table 3).

The education level of the participants $(P<0.001, r=$ $0.207)$ and their husbands $(P=0.001, r=0.160)$ showed a significant positive correlation with the total scores of QoL (Table 3).

The total scores of QoL $(P<0.001)$ and the scores in most of its domains were significantly lower in the group with a less-than-adequate family monthly income, comparing to the group with sufficient income levels (Table 4).

Similarly, there was a positive correlation between family monthly income and the total scores of QoL $(P<0.001, r=0.218)$, as well as the scores in all of its domains except social relations $(P<0.001)$.

The total score of QoL $(P=0.023)$, along with the scores in the physical-health and psychological-health domains $(P<0.001$ and $P=0.009$, respectively), was significantly lower among the housewives compared to the employed women (Table 4).

There was a significant reverse correlation between the scores of QoL (total scores and the scores in all of its domains) and the frequency of pregnancy (gravid) and delivery $(P<0.001, r=-0.177$ and $P=0.001, r=-$ 0.165 , respectively, with the total QoL scores). Furthermore, the total scores of QoL and the scores in its environmental-health domain were reversely correlated with the frequency of stillbirth $(P=0.037, r=-0.104$ and $P=0.009, r=-0.129$, respectively) (Table 3 ).

The same type of correlation existed between the scores of QoL (total scores and all of the domain scores) and frequency of vaginal delivery $(P=0.001, r=-0.161$ with the total scores) (Table 3).
The scores of QoL were negatively correlated with waist-to-hip ratio $(P<0.001, r=-0.195$ with the total scores), but not significantly correlated with body mass index (BMI) (Table 3). It must be noted that the results mentioned above were yielded by unadjusted analyses.

Multiple linear regression showed that the total score of QoL decreased with inadequate income $(P=0.002$, $\mathrm{B}=2.318)$, waist-to-hip ratio $(P=0.004, \mathrm{~B}=-11.380)$, and the total score of MRS $(P<0.001, \mathrm{~B}=-0.420)$. The results of the multiple linear regression are shown in Table 5.

\section{Discussion}

This study showed that out of various anthropometric, socio-economic and reproductive characteristics that may have influence the quality of life of postmenopausal women, waist-to-hip ratio, the severity of menopausal symptoms, and the adequacy of monthly household income are the most remarkable ones.

The results showed that QoL is negatively associated with the severity of menopausal symptoms. That is, for every one unit increase in the total score of MRS, the total score of QoL decreased by 0.420 units. This finding is in agreement with those of multiple studies showing the severity of menopausal symptoms to be in a negative association with QoL [29, 30, 32, 33, 38-40]. According to some estimates, 50 to $80 \%$ of women experience menopausal symptoms (physical or psychological), leading to a decline in QoL [15]. Menopause affects all aspects of health, and our study shows that QoL among postmenopausal women is jeopardized with the emergence of menopausal symptoms.

This study found family monthly income to be associated with QoL. The total score of QoL was 2.318 units higher among the women with adequate or higher monthly income comparing to those with less-thanadequate monthly income. The relationship between income/economic status and QoL has been confirmed in several studies [11, 26, 27, 34, 41, 42], all of which are consistent with our study. This finding might stem from the fact that women with higher socioeconomic statuses, due to proper nutrition and timely referrals to medical specialists, find it easier to cope with the side effects of

Table 2 Quality of life (WHOQOL-BREF) and Menopause Rating Scale (MRS) (N=405)

\begin{tabular}{lllll}
\hline $\begin{array}{l}\text { The severity of } \\
\text { menopausal } \\
\text { symptoms }\end{array}$ & Quality Of life & & & \\
\cline { 2 - 5 } & Physical health & Psychological health & Social relations & Environment \\
\hline Somatic & $r$ & $r$ & $r$ & -0.125 \\
Psychological & $-0.399^{* * *}$ & $-0.167^{* *}$ & $-0.188^{* * *}$ & $-0.183^{* * *}$ \\
Urogenital & $-0.421^{* * *}$ & $-0.383^{* * *}$ & $-0.251^{* * *}$ & $-0.147^{* *}$ \\
Total score & $-0.266^{* * *}$ & $-0.196^{* * *}$ & $-0.319^{* * *}$ & $-0.390^{* * *}$ \\
\hline
\end{tabular}

${ }^{*} P<0.05$. ${ }^{* *} P<0.01$. ${ }^{* *} P<0.001$. Test: Pearson correlation coefficient 
Table 3 Unadjusted correlation between QoL with demographic and reproductive characteristics $(N=405)$

\begin{tabular}{|c|c|c|c|c|c|}
\hline \multirow[t]{3}{*}{ Characteristics } & \multicolumn{5}{|l|}{ Quality of life } \\
\hline & Physical health & Psychological health & Social relations & Environment & Total score \\
\hline & $r$ & $r$ & $r$ & $r$ & $r$ \\
\hline \multicolumn{6}{|l|}{ Test: Pearson correlation coefficient } \\
\hline Age (years) & -0.054 & -0.090 & -0.052 & -0.067 & -0.081 \\
\hline Husband's age (years) & -0.056 & -0.028 & -0.054 & -0.083 & -0.069 \\
\hline Age at menopause (years) & -0.046 & -0.058 & -0.042 & -0.037 & -0.057 \\
\hline Duration of menopause (months) & -0.076 & $-0.140^{* *}$ & -0.089 & $-0.109^{*}$ & $-0.127^{*}$ \\
\hline Duration of marriage (years) & -0.068 & -0.078 & -0.007 & -0.034 & -0.057 \\
\hline $\mathrm{BMI}(\mathrm{Kg} / \mathrm{m}$ 2) & -0.078 & -0.029 & -0.067 & -0.088 & -0.013 \\
\hline Waist to Hip Ratio & $-0.160^{* *}$ & $-0.210^{* * *}$ & $-0.112^{*}$ & $-0.151^{* *}$ & $-0.195^{* * *}$ \\
\hline \multicolumn{6}{|l|}{ Test: Spearman's correlation coefficient } \\
\hline Education level of the women & $0.166^{* *}$ & $0.254^{* * *}$ & 0.084 & $0.266^{* * *}$ & $0.207^{* * *}$ \\
\hline Education level of the husbands & $0.120^{*}$ & $0.208^{* * *}$ & 0.049 & $0.199^{* * *}$ & $0.160^{* *}$ \\
\hline Gravida & $-0.182^{* * *}$ & $-0.158^{* *}$ & $-0.119^{*}$ & $-0.173^{* * *}$ & $-0.177^{* * *}$ \\
\hline Parity & $-0.183^{* * *}$ & $-0.157^{* *}$ & $-0.103^{*}$ & $-0.164^{* *}$ & $-0.165^{* *}$ \\
\hline frequency of stillbirth & -0.089 & -0.055 & -0.070 & $-0.129^{* *}$ & $-0.104^{*}$ \\
\hline Vaginal delivery & $-0.181^{* * *}$ & $-0.136^{* *}$ & $-0.108^{*}$ & $-0.152^{* *}$ & $-0.161^{* *}$ \\
\hline
\end{tabular}

Table 4 Quality of life based on socio-economic factors

\begin{tabular}{|c|c|c|c|}
\hline \multirow[t]{2}{*}{ Quality Of life } & \multicolumn{2}{|c|}{ The adequacy of Monthly household income } & \multirow{2}{*}{$\begin{array}{c}t \text {-Test } \\
(P)\end{array}$} \\
\hline & $\begin{array}{l}\text { Less than adequate } \\
\qquad N=265\end{array}$ & $\begin{array}{c}\text { Adequately or More } \\
\quad N=136\end{array}$ & \\
\hline Physical health & 14.14 & 14.55 & 0.106 \\
\hline Psychological health & 12.35 & 13.54 & $<0.001$ \\
\hline Social relations & 13.89 & 14.54 & 0.016 \\
\hline Environment & 12.99 & 14.19 & $<0.001$ \\
\hline Total score & 53.37 & 56.82 & $<0.001$ \\
\hline \multirow[t]{2}{*}{ Quality Of life } & \multicolumn{2}{|c|}{ Occupation } & $t$-Test \\
\hline & $\begin{array}{l}\text { Housewife } \\
N=324\end{array}$ & $\begin{array}{c}\text { Employed } \\
\quad N=81\end{array}$ & \\
\hline Physical health & 14.07 & 15.11 & $<0.001$ \\
\hline Psychological health & 12.62 & 13.28 & 0.009 \\
\hline Social relations & 14.09 & 14.16 & 0.838 \\
\hline Environment & 13.34 & 13.59 & 0.299 \\
\hline Total score & 54.12 & 56.15 & 0.023 \\
\hline \multirow[t]{2}{*}{ Quality Of life } & \multicolumn{2}{|c|}{ Husband's job } & $t$-Test \\
\hline & $\begin{array}{l}\text { Employed } \\
N=303\end{array}$ & $\begin{array}{l}\text { Retired or unemployed } \\
\qquad N=101\end{array}$ & $(P)$ \\
\hline Physical health & 14.19 & 14.51 & 0.238 \\
\hline Psychological health & 12.66 & 13.05 & 0.098 \\
\hline Social relations & 14.07 & 14.25 & 0.535 \\
\hline Environment & 13.22 & 13.55 & 0.053 \\
\hline Total score & 54.13 & 55.70 & 0.157 \\
\hline
\end{tabular}


Table 5 Factors associated with quality of life among postmenopausal women (multiple linear regression) $(N=405)$

\begin{tabular}{|c|c|c|c|}
\hline \multirow[t]{2}{*}{ Quality of life } & \multirow[t]{2}{*}{ Variables } & \multicolumn{2}{|c|}{ Multiple linear regression } \\
\hline & & B & $P$ value \\
\hline \multirow[t]{2}{*}{ Physical health } & Waist-to-hip ratio & -2.641 & 0.046 \\
\hline & Total score of MRS & -0.154 & $<0.001$ \\
\hline \multirow[t]{3}{*}{ Psychological health } & The adequacy of monthly household income ${ }^{a}$ & 0.816 & $<0.001$ \\
\hline & Waist-to-hip ratio & -3.264 & 0.005 \\
\hline & Total score of MRS & -0.098 & $<0.001$ \\
\hline \multirow[t]{3}{*}{ Social relations } & The adequacy of monthly household income & 0.610 & 0.032 \\
\hline & Waist-to-hip ratio & -3.244 & 0.034 \\
\hline & Total score of MRS & -0.115 & $<0.001$ \\
\hline \multirow[t]{2}{*}{ Environment } & The adequacy of monthly household income & 0.950 & $<0.001$ \\
\hline & Total score of MRS & -0.053 & $<0.001$ \\
\hline \multirow[t]{3}{*}{ Total score } & The adequacy of monthly household income & 2.318 & 0.002 \\
\hline & Waist-to-hip ratio & -11.380 & 0.004 \\
\hline & Total score of MRS & -0.420 & $<0.001$ \\
\hline
\end{tabular}

${ }^{a}$ Classification of the adequacy of Monthly household income: 0 (Zero). Less than adequate; 1 . Adequately or more

menopause [27]. Moreover, favorable economic conditions are often associated with better-paying jobs and higher education levels in couples, which could in turn ease their adaptation to the changes during menopause and senility. What is well established is that QoL during menopause is influenced in consequential ways by physical, emotional, social, and economic factors [26].

No significant association was found between QoL and BMI, which is consistent with the findings of Fallahzade et al. [27] and Golmakany et al. [35], but inconsistent with those of several other studies [28, 31, 41, 43, 44]. In study of Fallahzadeh [28], women with a BMI equal to or less than $18.5 \mathrm{~kg} / \mathrm{m}^{2}$ had better QoL.

The finding demonstrated waist-hip ratio, however, to be inversely associated with QoL, so that with each unit increase in waist-hip ratio the total score of QoL decreased by 11.380 units. Considering that waist-to-hip ratio is an indicator of obesity, QoL could be theoretically tied to obesity, but there remains a need for further investigation on this front.

The results also showed a negative correlation between duration of menopause and the total score of QoL, as well as its psychological-health and environment domains. This finding has been confirmed by other studies $[36,37]$. Some studies, however, showed that women whose menopause was 5 years old or older showed better quality of life $[28,43]$. While their study examined duration of menopause in two groups and with a fiveyear-old threshold, our study was performed with more precision and duration of menopause was calculated up to months. Therefore, this controversy could be attributed to the different method of data analysis and the study population.
There was not any significant correlation between age and QoL, which does not correspond with a number of studies [11, 27, 30, 37, 41, 43, 45, 46] and could be the result of differences in study population and datacollection tools.

A positive correlation was found between level of education (among the women and their spouses) and the total score of QoL along with all of its domain scores except the domain of relationships. This finding has also been confirmed elsewhere [11, 15, 27, 30, 36, 37, 41, 43, 46, 47].

Surely women with higher education levels have greater access to credible sources of information and health resources, and hence are more equipped to deal with the complications and symptoms of menopause, which in turn leads to better QoL [27]. On the other hand, higher education is often synonymous with higher income levels and more opportunities in one's professional and social lives [11], which could also improve QoL.

The present study revealed that the total scores of QoL and the scores in the physical- and psychologicalhealth domains were lower among the housewives compared with the employed women. The spouses' occupations, however, showed no correlation with the QoL of the participating postmenopausal women. The relationship between employment status and QoL has been examined by several studies [27, 36, 41, 43, 46, 48-50], most of which found employed women to have a better QoL than housewives $[27,36,43,48]$, which is consistent with our study.

Norozi et al. have showed that retired postmenopausal women enjoy a better QoL than housewives [46], while the study of Shobeiri et al. found that QoL is stronger among housewife postmenopausal women comparing to employed women [41]. 
It could be speculated that a job or responsibility in an organization boosts confidence among middle-aged women and helps to improve their QoL [46]. The employed women seemed that had better social support [41]. Housewives, on the other hand, are less exposed to the social environment outsides their homes and are mostly occupied with household chores, personally carrying out many of the tasks that working, financially independent women often delegate to others.

The side effects of menopause could be associated with the burdens of housework, which further complicate matters and diminish QoL. Working women also tend to have better mental health than stay-at-home ones [27], and given their routine exposure to social settings outside the home, are better able to withstand the symptoms of menopause.

This study showed that QoL is in a negative correlation with the frequencies of pregnancy (gravida), delivery (parity), and vaginal birth. Consistent with our findings, the Fallahzadeh et al. study [27] showed that the frequency of pregnancy could be correlated with QoL, and Monterrosa-Castro [31] showed that QoL significantly decreases with parity. Some studies also showed that number of children was inversely associated QoL in postmenopausal women [41, 51]. Given the association of the number of children with the frequencies of pregnancies and delivery, this result is consistent with the result of the present study.

These findings indicate that multiparity and multiple childbirths could cause physical and psychological impairments and hence have a negative impact on QoL. Higher number children could increase parental stress and responsibility as well as financial problems [52]. Mothers' concerns regarding childcare - providing a decent life for them, paying attention to comfort them - always take precedence over their own convenience, thus correlating with their QoL. It could also be inferred that the odds of stillbirth are increased with every pregnancy, as a significant negative correlation was found between QoL and the frequency of stillbirth.

\section{Strengths and limitations}

To mention the strengths of the present study, we excluded women whose menopause was longer than 3 years at the time of the study. It could have weakened the effects of aging on QoL. In addition, our study was conducted among general, Iranian postmenopausal women, which decreased participation bias.

Regarding limitations, the present study was conducted in two cities located in northern Iran, and its results may not be generalizable to other communities with different attitudes, customs, cultures, and lifestyles. Another important limitation of this study was that the present study was cross-sectional study and this design did not permit the assessment of the temporal sequence of QoL and effective factors, making it impossible to assess causal relations.

\section{Conclusion}

Menopause and its symptoms tend to impact on quality of life, a metric that is under the influence of multiple personal and social factors among postmenopausal women. Some factors have a negative effect on quality. These factors include the severity of menopausal symptoms, duration of menopause, gravida, parity, frequency of stillbirth, vaginal delivery, and waist-to-hip ratio. Other factors have a positive effect on the quality of life, such as the educational level of the postmenopausal women and that of their spouses, and level of monthly family income. Thus, appropriate interventions need to be made by way of public-health policies that aim to mitigate menopausal symptoms and maintain quality of life among these women. In this regard, these effective factors should be considered for planning of programs to improve the quality of life among postmenopausal women.

\section{Abbreviations \\ QoL: Quality of life; WHO: World health organization; WHOQOL-BREF: World health organization quality of life-BREF; MRS: Menopause rating scale; ANOVA: Analysis of variance; ICC: Intraclass correlation coefficient; BMI: Body mass index}

\section{Acknowledgements}

The authors acknowledge the postmenopausal women residing in Chalous and Noshahr, Iran, for their participation in this study.

\section{Authors' contributions}

SN developed the project, designed the concept and study, carried out data collection, carried out data analysis, and prepared the first and revised drafts of the manuscript. MS and FRT developed the project, designed the concept and study, managed the data, revised drafts of the manuscript, edited critically the manuscript. HAM managed data analysis. All authors have read and approved the final manuscript.

\section{Funding}

Not applicable.

\section{Availability of data and materials}

The datasets used and/or analysed during the current study are available from the corresponding author on reasonable request.

Ethics approval and consent to participate

The study was approved by the ethics committee of Shahid Beheshti University of Medical Sciences, with the code "sbmu.rec.1392.293," on September 8, 2013. Written informed consents were, also, obtained from the respondents.

\section{Consent for publication}

Not applicable.

\section{Competing interests}

The authors declare no conflict of interest.

\section{Author details}

'Department of Midwifery, Chalous Branch, Islamic Azad University, Chalous, Iran. ${ }^{2}$ Midwifery and Reproductive Health Research Center, Department of Midwifery and Reproductive Health, School of Nursing and Midwifery, Shahid 
Beheshti University of Medical Sciences, Vali-Asr Avenue, Cross of Vali-Asr and Hashemi Highway, Opposite to Rajaee Heart Hospital, Tehran 1996835119, Iran. ${ }^{3}$ Reproductive Endocrinology Research Center, Research Institute for Endocrine Sciences, Shahid Beheshti University of Medical Sciences, Tehran, Iran. ${ }^{4}$ Department of Biostatistics, School of Paramedicine, Shahid Beheshti University of Medical Sciences, Tehran, Iran.

Received: 6 January 2020 Accepted: 26 April 2020

Published online: 14 May 2020

\section{References}

1. WHOQoL Group. Study protocol for the World Health Organization project to develop a quality of life assessment instrument (WHOQOL). Qual Life Res. 1993;2:153-9.

2. Chen Y, Lin SQ, Wei Y, Gao HL, Wu ZL. Menopause-specific quality of life satisfaction in community-dwelling menopausal women in China. Gynecol Endocrinol. 2007;23(3):166-72.

3. Polinder S, Haagsma JA, van Klaveren D, Steyerberg EW, Van Beeck EF. Health-related quality of life after TBI: a systematic review of study design, instruments, measurement properties, and outcome. Popul Health Metrics. 2015;13(1):4.

4. Dumuid D, Olds T, Lewis LK, Martin-Fernández JA, Katzmarzyk PT, Barreira T, et al. Health-related quality of life and lifestyle behavior clusters in schoolagedchildren from 12 countries. J Pediatr. 2017;183:178-83.

5. Barcaccia B, Esposito G, Matarese M, Bertolaso M, Elvira M, De Marinis MG. Defining quality of life: a wild-goose chase? Eur J Psychol. 2013;9(1):185203.

6. Park K. Park's textbook of preventive and social medicine. 23rd ed. India: Bhanot Publishers; 2015.

7. Kontis V, Bennett JE, Mathers CD, Li G, Foreman K, Ezzati M. Future life expectancy in 35 industrialised countries: projections with a Bayesian model ensemble. Lancet. 2017;389(10076):1323-35.

8. Wang X, Ran S, Yu Q. Optimizing quality of life in perimenopause: lessons from the east. Climacteric. 2019;22(1):34-7.

9. Webster AD, Finstad DA, Kurzer MS, Torkelson CJ. Quality of life among postmenopausal women enrolled in the Minnesota green tea trial. Maturitas. 2018;108:1-6.

10. Schneider $H$, Birkhäuser M. Quality of life in climacteric women. Climacteric. 2017;20(3):187-94.

11. Gobbens RJ, Remmen R. The effects of sociodemographic factors on quality of life among people aged 50 years or older are not unequivocal: comparing SF-12, WHOQOL-BREF, and WHOQOL-OLD. Clin Interv Aging. 2019:14:231-9

12. Berek JS. Berek \& Novak's Gynecology. 16th ed. Philadelphia: Lippincott Williams \& Wilkins (LWW); 2019.

13. Monteleone P, Mascagni G, Giannini A, Genazzani AR, Simoncini T. Symptoms of menopause-global prevalence, physiology and implications. Nat Rev Endocrinol. 2018;14(4):199-215.

14. Ozcan H. Healthy life style behaviors and quality of life at menopause. Int J Caring Sci. 2019;12(1):492-500.

15. Jenabi E, Shobeiri F, Hazavehei S, Roshanaei G. Assessment of questionnaire measuring quality of life in menopausal women: a systematic review. Oman Med J. 2015;30(3):151-6.

16. Nazarpour S, Simbar M, Tehrani FR, Alavi MH. The relationship between menopausal symptoms and sexual function. Women Health. 2018;58(10): 1112-23.

17. WHOQOL group. Measuring Quality of Life; The development of the World Health Organization Quality of Life Instrument (WHOQOL); 1992.

18. WHOQOL group: WHOQOL-BREF Introduction, Administration and scoring Field Trial version; 1996. http://www.who.int/mental_health/media/en/76. pdf. Accessed 25 May 2019.

19. Heinemann LA, Potthoff $P$, Schneider HP. International versions of the Menopause Rating Scale (MRS). Health Qual Life Outcomes. 2003;1:28.

20. Heinemann $K$, Ruebig A, Potthoff $P$, Schneider HP, Strelow F, Heinemann LA, Do MT. The menopause rating scale (MRS) scale: a methodological review. Health Qual Life Outcomes. 2004;2:45.

21. Potthoff P, Heinemann LA, Schneider HP, Rosemeier HP, Hauser GA. The menopause rating scale (MRS II): methodological standardization in the German population. Zentralbl Gynakol. 2000;122(5):280-6.
22. Bonomi AE, Patrick DL, Bushnell DM, Martin M. Validation of the United States' version of the World Health Organization quality of life (WHOQOL) instrument. J Clin Epidemiol. 2000;53(1):1-12.

23. Nejat S, Montazeri A, Holakouie Naieni K, Mohammad K, Majdzadeh S. The World Health Organization quality of life (WHOQOL-BREF) questionnaire: translation and validation study of the Iranian version. J Sch Public Health Inst Public Health Res (SJSPH). 2006;4(4):1-12.

24. Soltani R, Kafee S, Salehi I, Karashki H, Rezaee S. Survey the quality of life in Guilan university students. J Guilan Univ Med Sci. 2010;19(75):25-35.

25. Masjoudi M, Amjadi MA, Leyli EKN. Severity and frequency of menopausal symptoms in middle aged women, Rasht. Iran J Clin Diagn Res: JCDR. 2017; 11(8):QC17.

26. Abdi N, Solhi M. The quality of life in postmenopausal women in Tehran. J Health Health Promotion. 2014;2(2):87-96.

27. Fallahzade H, Dehghani Tafti A, Dehghani Tafti MH, HF S, Hosseini H. Factors associated with quality of life in postmenopausal women in Yazd in 2008. J Shahid sadoghi Yazd Univ Med Sci. 2011;18(6):552-8.

28. Fallahzadeh H. Quality of life after the menopause in Iran: a population study. Qual Life Res. 2010;19(6):813-9.

29. Miranda JS, Ferreira Mde L, Corrente JE. Quality of life of postmenopausal women attended at primary health care. Rev Bras Enferm. 2014;67(5):803-9.

30. Mohammadalizadeh Charandabi S, Rezaei N, Hakimi S, Montazeri A, Taheri $\mathrm{S}$, Taghinejad $\mathrm{H}$, et al. Quality of life of postmenopausal women and their spouses: a community-based study. Iran Red Crescent Med J. 2015;17(3): e21599.

31. Monterrosa-Castro A, Romero-Pérez I, Marrugo-Flórez M, Fernández-Alonso AM, Chedraui P, Pérez-López FR. Quality of life in a large cohort of midaged Colombian women assessed using the Cervantes scale. Menopause. 2012;19(8):924-30.

32. Ngai FW. Relationships between menopausal symptoms, sense of coherence, coping strategies, and quality of life. Menopause. 2019;26(7): 758-64.

33. Rathnayake N, Lenora J, Alwis G, Lekamwasam S. Prevalence and severity of menopausal symptoms and the quality of life in middle-aged women: a study from Sri Lanka. Nurs Res Pract. 2019;2019:1-9.

34. Farotimi AA, Akinbade MO, Okueso GO. Determinants of quality of life among menopausal market women traders in a South-Western town, Nigeria. J Adv Med Med Res. 2019;31(12):1-9.

35. Golmakany A, Shariati Sarcheshmeh M, Marouzi P, Rezaie ST. Body mass index and its relation to menopausal women's quality of life. J Holist Nurs Midwifery. 2016;26(1):48-55.

36. Haghi HB, Hakimi S, Mirghafourvand M, Mohammad-Alizadeh S, Charandabi MF. Comparison of quality of life between urban and rural menopause women and its predictors: a Population Base study. Int J Women Health Reprod Sci. 2017;5(2):137-42.

37. Kabodi S, Ajami E, Zakiei A, Zangeneh A, Saeidi S. Women's quality of life in menopause with a focus on hypertension. J Obstet Gynaecol India. 2019; 69(3):279-83.

38. Ibrahim ZM, Sayed Ahmed WA, El-Hamid SA. Prevalence of menopausal related symptoms and their impact on quality of life among Egyptian women. Clin Exp Obstet Gynecol. 2015;42(2):161-7.

39. Jayabharathi B, Judie A. Severity of menopausal symptoms and its relationship with quality of life in post-menopausal women-a community based study. Int J Pharm Clin Res. 2016;8(1):33-8.

40. Moral E, Delgado J, Carmona F, Caballero B, Guillán C, González P, et al. Genitourinary syndrome of menopause. Prevalence and quality of life in Spanish postmenopausal women. The GENISSE study. Climacteric. 2018; 21(2):167-73.

41. Shobeiri F, Jenabi E, Hazavehei SMM, Roshanaei G. Quality of life in postmenopausal women in Iran: a population-based study. J Menopausal Med. 2016;22(1):31-8.

42. Santos RS, Andrade MM, Ribeiro KMOB, Nascimento RA, Vieira MCA, Câmara SMA, et al. Relationship between vestibular dysfunction and quality of life in climacteric women. Cien Saude Colet. 2020;25(2):645-54.

43. Mirhaghjou SN, Niknami M, Moridi M, Pakseresht S, Kazemnejad E. Quality of life and its determinants in postmenopausal women: a population-based study. Appl Nurs Res. 2016;30:252-6. https://doi.org/10.1016/j.apnr.

44. Klemp JR, Myers JS, Fabian CJ, Kimler BF, Khan QJ, Sereika SM, et al. Cognitive functioning and quality of life following chemotherapy in pre-and peri-menopausal women with breast cancer. Support Care Cancer. 2018; 26(2):575-83. 
45. Direkvand-Moghadam A, Delpisheh A, Montazeri A, Sayehmiri K. Quality of life among Iranian infertile women in postmenopausal period: a crosssectional study. J Menopausal Med. 2016;22(2):108-13.

46. Norozi E, Mostafavi F, Hasanzadeh A, Moodi M, Sharifirad G. Factors affecting quality of life in postmenopausal women, Isfahan, 2011. J Educ Health Promot. 2013;2:58. https://doi.org/10.4103/2277-9531.120857.

47. Li S, Ho SC, Sham A. Relationship between menopause status, attitude toward menopause, and quality of life in Chinese midlife women in Hong Kong. Menopause. 2016;23(1):67-73.

48. Alaeenejad A, Farahaninia M, Janmohammadi S, Haghani H. Relationship between health-promoting behaviors and quality of life in postmenopausal women. J Client-Centered Nurs Care. 2017;3(4):269-76.

49. Shukla R, Ganjiwale J, Patel R. Prevalence of postmenopausal symptoms, its effect on quality of life and coping in rural couple. J Midlife Health. 2018; 9(1):14-20.

50. Tarigan I, Sanusi SR. Dominant Factors Affecting In Quality Of Life Menopause Women. In: 2nd Public Health International Conference (PHICo 2017). Dec 2017: Atlantis Press; 2017. https://doi.org/10.2991/phico-17.2018.16.

51. Mohammad-Alizadeh-Charandabi S, Rezaei N, Hakimi S, Montazeri A. Predictors of health-related quality of life in postmenopausal women: a population-based study. J Caring Sci. 2012;1 (4):201-8.

52. Hsiao Y-J, Higgins K, Pierce T, Whitby PJS, Tandy RD. Parental stress, family quality of life, and family-teacher partnerships: families of children with autism spectrum disorder. Res Dev Disabil. 2017;70:152-62.

\section{Publisher's Note}

Springer Nature remains neutral with regard to jurisdictional claims in published maps and institutional affiliations.

Ready to submit your research? Choose BMC and benefit from:

- fast, convenient online submission

- thorough peer review by experienced researchers in your field

- rapid publication on acceptance

- support for research data, including large and complex data types

- gold Open Access which fosters wider collaboration and increased citations

- maximum visibility for your research: over $100 \mathrm{M}$ website views per year

At $\mathrm{BMC}$, research is always in progress.

Learn more biomedcentral.com/submissions 